\title{
Measurements of spectral snow albedo at Neumayer, Antarctica
}

\author{
S. Wuttke ${ }^{1, *}$, G. Seckmeyer ${ }^{1}$, and G. König-Langlo ${ }^{2}$ \\ ${ }^{1}$ Institute for Meteorology and Climatology, University of Hannover, Herrenhäuser Str. 2, 30419 Hannover, Germany \\ ${ }^{2}$ Alfred-Wegener-Institut für Polar- und Meeresforschung, Institute for Polar and Marine Research, Bussestr. 24, 27570 \\ Bremerhaven, Germany \\ *now at: Alfred-Wegener-Institut für Polar- und Meeresforschung, Institute for Polar and Marine Research, Am \\ Handelshafen 12, 27570 Bremerhaven, Germany
}

Received: 25 October 2004 - Revised: 29 September 2005 - Accepted: 26 October 2005 - Published: 7 March 2006

\begin{abstract}
Spectral albedo in high resolution, from 290 to $1050 \mathrm{~nm}$, has been measured at Neumayer, Antarctica, $\left(70^{\circ} 39^{\prime} \mathrm{S}, 8^{\circ} 15^{\prime} \mathrm{W}\right)$ during the austral summer 2003/2004. At $500 \mathrm{~nm}$, the spectral albedo nearly reaches unity, with slightly lower values below and above $500 \mathrm{~nm}$. Above $600 \mathrm{~nm}$, the spectral albedo decreases to values between 0.45 and 0.75 at $1000 \mathrm{~nm}$. For one cloudless case an albedo up to 1.01 at $500 \mathrm{~nm}$ could be determined. This can be explained by the larger directional component of the snow reflectivity for direct incidence, combined with a slightly mislevelled sensor and the snow surface not being perfectly horizontal. A possible explanation for an observed decline in albedo is an increase in snow grain size. The theoretically predicted increase in albedo with increasing solar zenith angle (SZA) could not be observed. This is explained by the small range of SZA during albedo measurements, combined with the effect of changing snow conditions outweighing the effect of changing SZA. The measured spectral albedo serves as input for radiative transfer models, describing radiation conditions in Antarctica.
\end{abstract}

Keywords. Atmospheric composition and structure (Transmission and scattering of radiation) - Meteorology and atmospheric dynamics (Polar meteorology; Radiative process)

\section{Introduction}

The surface energy budget of the Antarctic continent is mainly controlled by the surface albedo, which is defined as the ratio of reflected to incident solar radiation. The mean surface albedo ( 300 to $3000 \mathrm{~nm}$ ) of Antarctic ice shelves is around 0.83 (Schmidt and König-Langlo, 1994). A change in prevailing climatic conditions can enhance feedback mechanisms, such as the ice-albedo feedback, which can be triggered by a change in temperature. Depending on the sign of the temperature change, the ice-albedo-feedback has contrary effects:

\section{Correspondence to: S. Wuttke}

(swuttke@awi-bremerhaven.de)
1. A rise in temperature leads to an enhancement in snow and sea ice melt, which, in turn, causes the surface albedo to decrease. More radiation is absorbed, increasing the energy budget and leading to a further rise in temperature.

2. A decrease in temperature leads to a greater production in sea ice, which, in turn, increases the albedo. Less radiation is absorbed, decreasing the energy budget and leading to a further cooling.

Even though a rise in overall global temperature has been detected (Houghton et al., 2001), regional trends deviate from the global one (Vaughan et al., 2001). For the region around the Antarctic Peninsula an increase in temperature, larger than the global temperature increase, has been observed (Jacka and Budd, 1998; Vaughan et al., 2001). Thus, the feedback mechanism under (1) is induced. Regional warming in the subantarctic region is also linked to higher precipitation in the Antarctic (Giorgi et al., 2001). Precipitation in the Antarctic falls in the form of snow. More freshly fallen snow increases the albedo, so that the feedback mechanism (2) is initiated. These two contradictory processes need to be considered when investigating climate related albedo effects in Antarctica.

Difficulties in predicting the extent of climate change exist due to deficiencies in coupling atmosphere, ocean and cryosphere. In particular, the improvement of the parameterisation of subgrid processes, such as clouds, radiation, precipitation and turbulence, is a major goal of current climate research (Lefebre et al., 2003). Kondratyev and Cracknell (1998) state the necessary accuracy of the albedo as input into global circulation models (GCMs) to be 0.02 to 0.04 . Small errors or changes in its value represent large fractional changes in absorbed solar radiation in the overall heat budget at the snow covered surface. Correct prescriptions and variability parameterisation of albedo are very difficult to achieve, based on a wide range of albedo variations and a limited database of albedo observations. This determines the urgency of surface albedo retrieval from satellite data, 
especially for remote regions such as the Arctic and Antarctic (Kondratyev and Cracknell, 1998).

High quality albedo measurements are vital in order to improve input parameterisations for GCMs as well as for validating satellite-based albedo retrievals. However, accurate ground-based albedo measurements are sparse, especially for the polar regions (Hansen and Nazarenko, 2004; Zhou et al., 2001). Li and Zhou (2003) also identify the lack of experimental investigations on spectral albedo in the field of snow and sea ice research. The available data cover only a small range of snow and ice types and few solar zenith angles (SZA).

Considering the spectral dependence of albedo with values reaching nearly unity in the ultraviolet (UV; $280-400 \mathrm{~nm}$ ) and visible (400-780 nm) part of the solar spectrum (Grenfell et al., 1994), it becomes clear that these spectral regions are mostly affected by changes in snow cover or sea ice extent.

The high albedo of a snow covered surface, especially in the UV and visible, has a large effect on the downwelling radiation, due to multiple reflections between the ground and the scattering atmosphere. Model calculations of ultraviolet irradiance for cloudless sky from Lenoble (1998) show enhancements in irradiance levels of nearly $50 \%$ at $320 \mathrm{~nm}$ for a snow covered surface, in comparison with snow free surfaces represented by a hypothetical surface albedo of zero.

A number of previous studies investigate the combined effect of surface albedo and clouds on UV irradiance:

- McKenzie et al. (1998):

Experimental studies have shown an increase in UV irradiance of approximately $40 \%$ due to a snow albedo of 0.8 . The enhancement in UV irradiance levels over a snow covered surface compared to a snow free surface amounts to $70 \%$ when a cloud cover is present.

- Kylling et al. (2000a):

Snow cover at Troms $\varnothing$, Norway increases the erythemal UV dose by more than $20 \%$. The maximum increase of a daily dose compared to snow free conditions is $63 \%$ for a cloudy day.

- Nichol et al. (2003):

The moderation of cloud reduction on UV irradiance in the Antarctic, due to a high surface albedo, is investigated. Compared to a cloudless case and a low surface albedo (0.05), a reduction of $40 \%$ in UV irradiance for cloudy conditions results. Increasing the surface albedo to 0.8 and 0.96 leads only to an attenuation by $20 \%$ and $10 \%$, respectively.

In mid-latitudes, vegetation, buildings and rocks prevent a complete snow cover of the surface. The albedo of such inhomogeneous surfaces is not uniform. Thus, efforts have been undertaken to estimate the effective albedo representative for such inhomogeneous surfaces (Degünther et al., 1998; Ricchiazzi and Gautier, 1998; Schwander et al., 1999; Smolskaia et al., 1999; Kylling et al., 2000b; Mayer and Degünther, 2000; Schmucki et al., 2001; Weihs et al., 2001; Smolskaia et al., 2003).
Surface UV albedo values of nearly 1.0 basically only occur in glaciated regions with homogeneous surfaces, such as Antarctica or Greenland. An albedo value of unity implies that all of the incident radiation is reflected. This means no fraction of the incoming irradiance is available for the energy budget of the surface. Due to the spectral dependence of downwelling irradiance and atmospheric (Rayleigh) scattering, highly resolved spectral albedo measurements are of particular importance to verify theoretical studies and to understand and quantify related radiation processes.

Antarctica is a favourable site for albedo measurements over pure snow, because compared to the Northern Hemisphere, the Antarctic snow is less contaminated with soot (Hansen and Nazarenko, 2004). So far, albedo measurements in the Antarctic have only been performed with broadband or filter spectroradiometers (Grenfell et al., 1994; Smolskaia et al., 1999; Zhou et al., 2001), but never with the same type of high-resolution instruments used for measuring spectral irradiance or radiance.

The aim of this study is to characterise the spectral albedo of natural clean snow in an Antarctic environment. The measured albedo spectra shall serve as a basis for further analyses of Antarctic spectral irradiance and radiance data. Spectral albedo measurements in a wavelength range from 290 to $1050 \mathrm{~nm}$ have been performed at the permanent German Antarctic Neumayer station $\left(70^{\circ} 39^{\prime} \mathrm{S}, 8^{\circ} 15^{\prime} \mathrm{W}\right)$ during the austral summer 2003/2004. Additionally, the snow albedo was measured with a Solar Light Model 501 Biometer with a response close to that of erythemally weighted irradiance (McKinlay and Diffey, 1987).

\section{Instruments}

\subsection{Spectroradiometer}

The scanning spectroradiometer of the Institute of Meteorology and Climatology (IMUK) of the University of Hannover, used to conduct spectral albedo measurements in Antarctica, is capable of measuring spectral irradiance in a wavelength range from 250 to $1050 \mathrm{~nm}$, thus covering the part of the solar spectrum where high albedo values are expected. It basically contains four components. They consist of the entrance optics, a double monochromator, radiation detectors and devices to control the measurements and store the data.

The entrance optics consist of a shaped Teflon diffuser, which is protected by a quartz dome. This diffuser is optimized for a low cosine error. The deviation from the ideal cosine response is shown in Fig. 1 for three wavelengths. For $320 \mathrm{~nm}$, the cosine error is less than 5\% for solar zenith angles below $85^{\circ}$. The cosine error for larger wavelengths is slightly higher. Additional investigations in the IMUK radiation laboratory have been performed for wavelengths larger than $500 \mathrm{~nm}$. The deviation from the ideal cosine response remains below $5 \%$ for wavelengths below $900 \mathrm{~nm}$ and solar zenith angles of $85^{\circ}$. It starts to increase above $900 \mathrm{~nm}$. The very large deviations for $\theta>85^{\circ}$ are possible because of a low 
shadow ring. Thus, the results of spectral albedo measured with this input optics is not corrupted by a cosine error at least up to $900 \mathrm{~nm}$, which is the main wavelength region of interest in this study.

The radiation is guided into the entrance slit of the monochromator through an optical fiber. The diffuser is heated for the temperature, never to sink below $30^{\circ} \mathrm{C}$ to avoid humidity affecting the measurement.

The central element of the spectroradiometer is a model TMc300 double monochromator manufactured by Bentham Instruments Ltd. The double monochromator consists of two identical single Czerney Turner monochromators. The focal length is $300 \mathrm{~mm}$. The light enters the monochromator through a motorized entrance slit, which is set to $0.74 \mathrm{~mm}$ for wavelengths between 280 and $500 \mathrm{~nm}$ and to $1.48 \mathrm{~mm}$ for wavelengths between 500 and $1050 \mathrm{~nm}$. These are also the widths of the exit slits. The middle slit is set to $1.85 \mathrm{~mm}$. For the wavelength ranges of 280 to $500 \mathrm{~nm}$ and 500 to $1050 \mathrm{~nm}$ holographic reflection gratings with 2400 and 1200 grooves per $\mathrm{mm}$ are employed in each monochromator, respectively. Stray light is suppressed by a number of baffles and the middle slit. The nominal bandwidth of the spectroradiometer is $0.5 \mathrm{~nm}$.

A photomultiplier tube (PMT), model DH-10-Te, is employed as a detector for the wavelength range from 280 to $500 \mathrm{~nm}$, whereas a silica diode is used from 501 to $1050 \mathrm{~nm}$. The output current of the PMT is further processed by a decadal current amplifier. This signal is converted to a digital signal, which can be further processed by computer.

To operate the spectroradiometer in a stable manner, it is placed inside a temperature controlled box. The temperature inside this box is held at $20^{\circ} \mathrm{C}\left( \pm 0.5^{\circ} \mathrm{C}\right)$ during measurements. Radiometric stability and wavelength accuracy are frequently tested. The responsivity of the spectroradiometer in the field is determined by scanning a $100 \mathrm{~W}$ halogen lamp, which is operated inside a portable field calibrator. The stability of the spectroradiometer is only of second order importance for albedo measurements because they are only relative measurements. Within a short time period, for example, one day, the spectroradiometer is radiometrically stable within $\pm 1 \%$.

A mercury line source can also be operated inside this field calibrator to test the wavelength alignment. In addition, the wavelength alignment is also tested by comparison with the Fraunhofer absorption lines of a high resolution extraterrestrial solar spectrum (Slaper et al., 1995).

The instrument design and performance is similar to instruments used within the Network for the Detection of Stratospheric Change (NDSC) (Seckmeyer et al., 1995; Bernhard and Seckmeyer, 1999) but, compared with these earlier built instruments, its major advantage is the more extensive wavelength range (Wuttke et al., 2006).

To assure the quality of the measured spectral data, the IMUK spectroradiometer has successfully taken part in two international intercomparisons for spectroradiometers. The first one was conducted in the context of the European Project "Quality Assurance of Spectral Ultraviolet

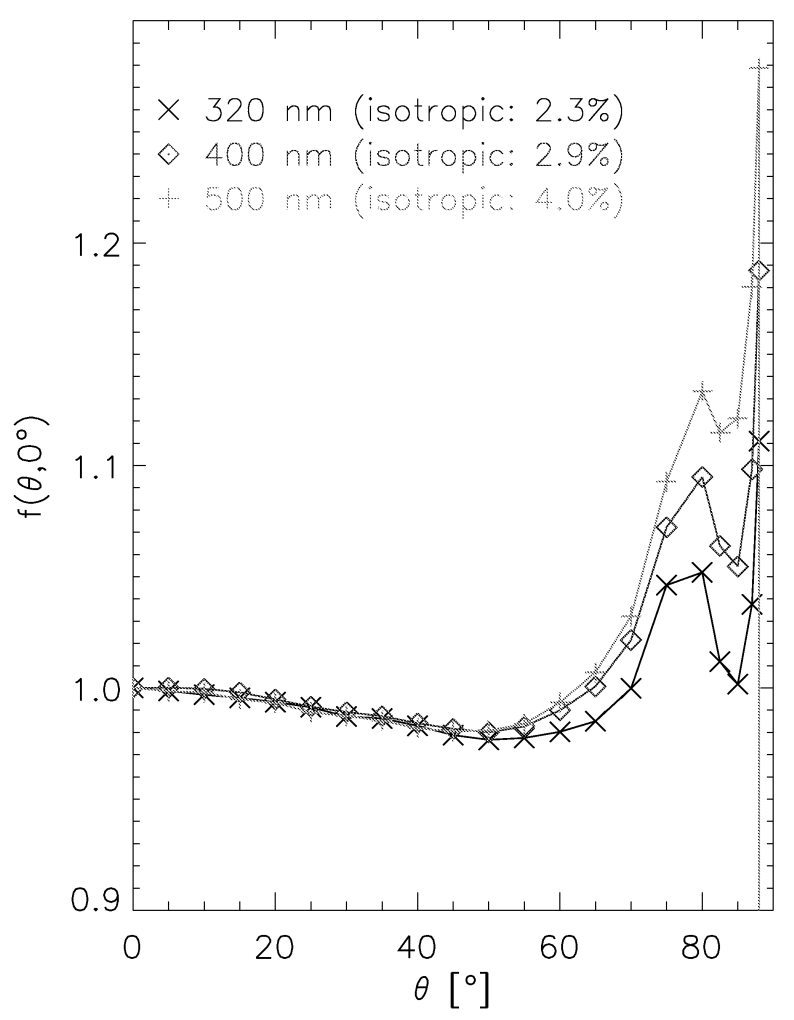

Fig. 1. The deviation from the ideal cosine response of the IMUK entrance optics for different wavelengths and one azimuth direction.

Measurements in Europe through the Development of a transportable unit" (QASUME; http://lap.physics.auth.gr/ qasume/Files/layouts/qasumereport.pdf). The second intercomparison was held near Boulder, Colorado, in June 2003. A publication on this intercomparison is being prepared. It has been shown that the IMUK spectroradiometer complies with the standards of the NDSC for UV spectroradiometry (McKenzie et al., 1997). It has been compared successfully to a NDSC spectroradiometer operated by the New Zealand Institute of Water and the Atmosphere (NIWA) and a spectroradiometer of the US National Science Foundation (NSF). The three instruments deviate from each other by less than $5 \%$ for a wide range of atmospheric conditions, and by $\pm 8 \%$ at $289 \mathrm{~nm}$ (Wuttke et al., 2006). Small differences in absolute irradiance levels and small wavelength shifts between the instruments are likely responsible for the somewhat larger deviations in the UVB. Overall, these deviations are well below the stated uncertainties of UV spectroradiometry (Bernhard and Seckmeyer, 1999; Bais et al., 2001). Recently, the IMUK spectroradiometer has been officially accredited as a mobile NDSC instrument.

\subsection{Biometer}

The broadband albedo measurements have been performed with a UV-Biometer Model 501 from Solar Light Co. (SL501). Its spectral response resembles the action spectrum 
for erythema, according to Commission Internationale de l'Eclairage (CIE). Thus, wavelengths in the UVB part of the electromagnetic spectrum (280 to $320 \mathrm{~nm}$ ) are the most sensitive ones. By approximation, the measured albedo for the erythemal range of solar radiation can also be applied for other biological reactions in the UVB range (Blumthaler and Ambach, 1988).

The data are logged at 1-minute-intervals. The radiation parameter stored is the erythemal dose in MED/min with a resolution of $10^{-3}$. The absolute calibration was performed by the manufacturer. Additionally, the date and time are saved, as well as the internal temperature of the detector.

\section{Methods}

\subsection{Experimental setup}

Albedo measurements have been performed directly on the area of Neumayer station and $6.2 \mathrm{~km}$ away at the ice edge. Neumayer is situated on the Ekström shelf ice on the Weddel Sea. Directly at the station, albedo has been measured with the spectroradiometer in a wavelength range from 280 to $1050 \mathrm{~nm}$, as well as with the SL501. At the ice edge, albedo measurements have been conducted with the SL501 only. At both sites, albedo measurements have been performed over a field of natural undisturbed snow.

According to Seckmeyer et al. (2001), albedo should be measured with two radiometers with cosine-weighted field of view at about 2 to $4 \mathrm{~m}$ height above the ground. To be able to detect up- as well as downwelling radiation, the sensors have been fixed to a rotatable rod, which was attached to a supporting frame roughly $2 \mathrm{~m}$ above the ground. The method of turning a radiation sensor has been applied previously, for example, by Blumthaler and Ambach (1988) or Feister and Grewe (1995). The collected light is led into the monochromator through an optical fibre. Due to the limited length of the optical fibre, the temperature stabilised box containing the spectroradiometer was set up only $2 \mathrm{~m}$ away from the footprint of the entrance optics. Thus, shadowing effects of the box need to be taken into account. The supporting frame is white to minimise the difference in reflectivity between the white snow surface and the supporting frame.

During the spectral albedo measurements, the SL501 was additionally mounted on the rod. While the cosine diffuser faced upwards, the SL501 measured reflected radiation. This way, the albedo could be determined independently with two different types of sensors.

\subsection{Measuring spectral albedo}

Albedo spectra have been collected either during cloudless or overcast sky conditions. In this way, it is assured that the atmospheric conditions are sufficiently stable in order to measure subsequent spectra of reflected and incident irradiance. The two most important influencing factors are the change in SZA and the presence of clouds. Also, the length of the spectra recorded for the calculation of albedo has to be considered. Four different data collection protocols concerning wavelength range and step have been developed and applied.

1. From 290 to $400 \mathrm{~nm}$ in steps of $0.25 \mathrm{~nm}$; 1 January 2004: This range and step width has been chosen to be able to calculate erythemal irradiance from the spectral data. Thus, the albedo values measured with the SL501 can be compared to the ones derived from the spectral measurements (see Fig. 8). Reflected and incident irradiance have been recorded alternately because the scan time of one spectrum amounted to $9 \mathrm{~min}$.

2. From 304 to $306 \mathrm{~nm}, 319$ to $321 \mathrm{~nm}, 349$ to $351 \mathrm{~nm}$, 399 to $401 \mathrm{~nm}, 498$ to $500 \mathrm{~nm}$ in steps of $0.25 \mathrm{~nm} ; 694$ to $699 \mathrm{~nm}, 796$ to $804 \mathrm{~nm}, 996$ to $1004 \mathrm{~nm}$ in steps of $1 \mathrm{~nm}$; 2 to 4 January 2004: Choosing these wavelength steps, different wavelength regions could be covered with the routine wavelength step of 0.25 or $1 \mathrm{~nm}$. It took only 4 min to measure a spectrum with these wavelength steps. Therefore, two spectra of incident irradiance were measured before two spectra of reflected irradiance were recorded.

3. From 300 to $310 \mathrm{~nm}, 315$ to $325 \mathrm{~nm}, 345$ to $355 \mathrm{~nm}, 395$ to $405 \mathrm{~nm}, 490$ to $500 \mathrm{~nm}$ in steps of $0.25 \mathrm{~nm} ; 540$ to $590 \mathrm{~nm}, 670$ to $720 \mathrm{~nm}, 775$ to $825 \mathrm{~nm}, 975$ to $1025 \mathrm{~nm}$ in steps of $1 \mathrm{~nm}$; 5 January 2004: One spectrum takes $10 \mathrm{~min}$ to record, so that reflected and incoming irradiance are measured in an alternating order.

4. from 290 to $1050 \mathrm{~nm}$ in steps of $2 \mathrm{~nm} ; 6$ and 8 January 2004: The complete spectrum is covered in equidistant wavelength steps. Spectra of incident and reflected radiation have been measured alternately.

Two effects require correction. One is the change in SZA during the scan time to record a spectrum. The other is the shadowing effect caused by the equipment. Both effects will be addressed in the subsequent sections.

\subsubsection{SZA correction}

To account for the difference in SZA when measuring the reflected and downwelling spectrum, correction factors were calculated with the help of the radiative transfer model UVSPEC contained in the libRadtran package developed by Mayer and Kylling (2005). The model is freely available at http://www.libradtran.org. For each measured spectrum (downwelling or reflected) a spectrum of downwelling irradiance was modelled with a radiative transfer solver, applying the discrete ordinate method developed by Stamnes et al. (1988) for wavelengths lower than $500 \mathrm{~nm}$. For wavelengths larger than $500 \mathrm{~nm}$ the radiative transfer equation is solved according to pseudo-spectral calculations with a molecular absorption parameterisation adopted from Ricchiazzi et al. (1998). The atmosphere was considered aerosol free. The ozone column was taken from the Total Ozone Mapping Spectrometer (TOMS) data, which is available 
on the internet (ftp://jwocky.gsfc.nasa.gov/pub/eptoms/data/ overpass/OVP323_ept.txt). A homogeneous cloud layer has been included when applicable.

An albedo of 0.99 is used as input. To verify that the correction factor does not depend on the input albedo, spectral irradiance was modelled with an input albedo of 0.92 , in addition. All other input parameters remained constant. The ratio between the model spectrum with an input albedo of 0.99 and 0.92 is shown in Fig. 2. For all SZA occurring on a summer day at the location of Neumayer the ratio between spectra with an albedo of 0.99 and 0.92 is unity. A deviation of up to $1 \%$ is seen between spectra, including clouds and clear sky spectra. Thus, it is important to include stratiform clouds in the model spectra, to calculate the correction factor when applicable. The effect of the variable input albedo with unchanging cloud cover is zero. Thus, a surface albedo of 0.99 can be used as an input parameter.

There is no physical reason for the outlier at 10:00 UTC. To remove this error form the calculations a different theoretical approach is probably needed; however this is beyond our capabilities in this study and the outlier has no impact on the validity of our measurement results.

The agreement between libRadtran and the measured downwelling irradiance is summarised in Table 1. The mean ratio between model and measurement is between 0.95 and 1.05 for wavelengths between 320 and $800 \mathrm{~nm}$ for all SZA ranges that occurred during albedo measurements. The agreement between model and measurement could be further improved if input parameters were known more precisely. The larger deviation between measured and modelled irradiance at 305 and $1000 \mathrm{~nm}$ is due to the limited accuracy of the input total ozone column and the parameterisation of absorption, respectively.

To calculate the spectral correction factor $K_{\lambda}$, two consecutive modelled spectra of downwelling irradiance are divided by each other (Eq. 1):

$K_{\lambda}=\frac{M_{E}}{M_{R}}$.

$M_{E}$ is the spectrum modelled with the SZA according to the measured downwelling spectrum of irradiance. $M_{R}$ is the spectrum with the SZA according to the following measured reflected spectrum. In all modelled spectra, a wavelength dependent SZA has been used to account for the change in SZA during the period of recording a spectrum.

The modelled correction factors for 4 January 2004 are shown in Fig. 3. The upper panel shows the spectral correction factors at different times of the day. An enlargement of the UVB region is presented in the lower panel because the spectral dependence of the correction factor is strongest in the UVB. This is due to the combined effect of changing SZA and ozone absorption. It can be seen that the correction factor shifts with solar zenith angle.

The measured spectrum of downwelling irradiance is then divided by the spectral correction factor $K_{\lambda}$ (Eq. 2):

$E_{K}=\frac{E}{K_{\lambda}}$.

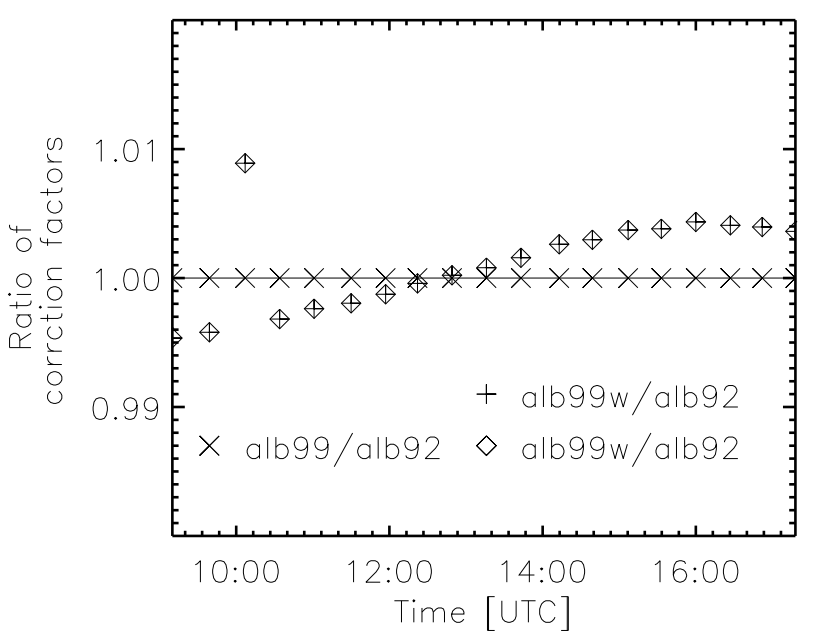

Fig. 2. Ratios of correction factors modelled with different input albedos for an example day. The abbreviations used in the legend represent the type of albedo and cloud input parameter for UVSPEC: alb92: albedo 0.92, no clouds; alb99: albedo 0.99, no clouds; alb92w: albedo 0.92, stratiform cloud cover; alb99w: albedo 0.99 , stratiform cloud cover.

$E$ is the measured spectrum of downwelling irradiance. $E_{K}$ is the spectrum corrected for the SZA at the time of recording the following reflected spectrum.

\subsubsection{Correction of the shadowing effect}

The temperature stabilised box of the spectroradiometer, as well as the metal rods, which hold the radiation sensors, are in the field of view of the sensors when measuring reflected radiation. Thus, they cause a shadowing effect, which has to be accounted for when calculating the albedo.

The measured reflected irradiance $R_{M}$ depends on both the irradiance reflected by the snow surface, $R_{S}$, and the irradiance reflected by the equipment, $R_{B}$. This dependence is stated in Eq. (3):

$R_{M}=\omega_{S} R_{S}+\omega_{B} R_{B}$

$\omega_{S}$ is the fraction of the half space covered by the snow surface and $\omega_{B}$ is the fraction of the half space of the equipment.

The reflected irradiance corrected for the shadowing effect is the reflected irradiance of the snow surface. Thus, to calculate the corrected reflected irradiance, Eq. (3) has to be solved for $R_{S}$, which is done in Eq. (4).

$R_{S}=\frac{R_{M}-\omega_{B} R_{B}}{\omega_{S}}$.

In order to estimate the correction of the measured reflected irradiance, the fraction of the half space covered by the equipment has to be known. It amounts to $3 \%$. For the remaining $97 \%$ of the half space, the irradiance reflected from the snow surface is measured. 
Table 1. Agreement between measured and modelled spectra of downwelling irradiance for small ranges of SZA. Listed are only specific wavelengths. The mean ratio $r_{m}$ between measurement and model, as well as the standard deviation $\sigma$, is listed.

\begin{tabular}{lllllll}
\hline $\begin{array}{l}\text { SZA range } \\
\text { wavelength [nm] }\end{array}$ & $\begin{array}{l}47-49.5^{\circ} \\
r_{m} \pm \sigma\end{array}$ & $\begin{array}{l}49.5-52^{\circ} \\
r_{m} \pm \sigma\end{array}$ & $\begin{array}{l}52-54.5^{\circ} \\
r_{m} \pm \sigma\end{array}$ & $\begin{array}{l}54.5-57^{\circ} \\
r_{m} \pm \sigma\end{array}$ & $\begin{array}{l}57-59.5^{\circ} \\
r_{m} \pm \sigma\end{array}$ & $\begin{array}{l}59.5-62^{\circ} \\
r_{m} \pm \sigma\end{array}$ \\
\hline 305 & $1.22 \pm 0.11$ & $1.17 \pm 0.17$ & $1.22 \pm 0.15$ & $1.23 \pm 0.16$ & $1.23 \pm 0.17$ & $1.25 \pm 0.17$ \\
320 & $0.97 \pm 0.24$ & $0.96 \pm 0.04$ & $0.98 \pm 0.04$ & $0.98 \pm 0.04$ & $0.97 \pm 0.04$ & $0.97 \pm 0.04$ \\
350 & $0.95 \pm 0.02$ & $0.95 \pm 0.03$ & $0.96 \pm 0.04$ & $0.96 \pm 0.03$ & $0.94 \pm 0.04$ & $0.95 \pm 0.04$ \\
400 & $1.00 \pm 0.02$ & $0.99 \pm 0.04$ & $1.02 \pm 0.03$ & $1.01 \pm 0.04$ & $0.99 \pm 0.05$ & $0.99 \pm 0.05$ \\
499 & $1.00 \pm 0.01$ & $1.01 \pm 0.03$ & $1.02 \pm 0.03$ & $1.02 \pm 0.04$ & $0.99 \pm 0.07$ & $1.01 \pm 0.08$ \\
695 & $1.03 \pm 0.02$ & $1.04 \pm 0.02$ & $1.06 \pm 0.03$ & $1.05 \pm 0.04$ & $1.04 \pm 0.07$ & $1.05 \pm 0.10$ \\
800 & $1.00 \pm 0.09$ & $1.01 \pm 0.03$ & $1.02 \pm 0.03$ & $1.02 \pm 0.04$ & $1.00 \pm 0.09$ & $1.03 \pm 0.09$ \\
1000 & $0.87 \pm 0.03$ & $0.88 \pm 0.04$ & $0.89 \pm 0.03$ & $0.89 \pm 0.04$ & $0.88 \pm 0.06$ & $0.90 \pm 0.07$ \\
\hline
\end{tabular}

In Eq. (4), the reflected irradiance of the equipment $R_{B}$ is not known, but can be estimated:

$R_{B}=\varrho_{\mathrm{Al}} E_{K}$

with $\varrho_{\mathrm{Al}}$ being the reflectance of sandblasted aluminium. $E_{K}$ is the incident irradiance (see Eq. 2). The main part of the equipment is the box, which is made of this type of aluminium. The reflectance of sandblasted aluminium is about 0.45 (König and Aden, 1999). It has a slight spectral dependence, which can be neglected for our application.

With the stated values for $\omega_{B}, \omega_{S}, \varrho_{\mathrm{Al}}$, and using Eqs. (4) and (5), the corrected reflected irradiance $R_{K}$ can finally be calculated by Eq. (6):

$R_{K}=R_{S}=\frac{R_{M}-0.0135 E_{K}}{0.97}$

Now the albedo $A_{K}$, taking into account the change in SZA and the shadowing effect, can be calculated with the downwelling irradiance corrected for solar zenith angle $E_{K}$ and the measured reflected irradiance corrected for the shadowing effect $R_{K}$ :

$A_{K}=\frac{R_{K}}{E_{K}}$

The spectral dependence of the albedo is not included in Eqs. (1) to (7). The spectral albedo $A_{\lambda}$ is defined here by referring both $R_{K}$ and $E_{K}$ to wavelength:

$A_{\lambda}=\frac{\frac{d R_{K}}{d \lambda}}{\frac{d E_{K}}{d \lambda}}=\frac{R_{K \lambda}}{E_{K \lambda}}$.

\subsection{Measuring broadband UV albedo}

The albedo values measured with the SL501 are also corrected for the effect of changing SZA and the shadowing effect, and determined according to Eq. (7). A value of erythemal irradiance is stored every minute by the data logger that belongs to the SL501. The sensor is rotated every 10 min. An 8-min mean value of erythemal irradiance has been calculated in order to determine the albedo. The first and last recorded values have been neglected to be sure that the act of turning the rod is not affecting the calculated albedo. The broadband UV albedo has been calculated according to Eq. (7), with $R_{K}$ and $E_{K}$ describing the 8-min means of reflected and incident erythemal irradiance, respectively.

The agreement for downwelling irrdiance in the broadband SL501 and the erythemal irradiance derived from the spectral data is shown in Table 2. It can be seen from Table 2 that the SL501 underestimates the downwelling irradiance compared to the spectroradiometer by $1-15 \%$, depending on SZA and the cloud situation. The largest deviations between the SL501 and the spectroradiometer occur at the largest SZA $\left(59.5^{\circ}\right.$ to $\left.62^{\circ}\right)$. This indicates a cosine error in the SL501 data. However, the cosine error should be clearer in the cloudless data, which is not the case. Overcast and cloudless situations have been distinguished according to the reading of a Haenni 111 sunshine duration sensor and a Laser Ceilograph by Impuls Physik GmbH. If the sunshine duration sensor indicated direct Sun, and the laser ceilograph did not detect any (low) clouds, the situation was considered cloudless. The upwelling irradiance detected by the SL501 is not affected as much by a nonideal cosine response, because of the missing direct component. The albedo derived from SL501 data should, therefore, be underestimated.

The angular response has not been measured for this specific SL501. However, there is no indication that the instrument will not have an angular response that differs much from the angular response typical for such instruments (Seckmeyer et al., 2005). The cosine error of broadband instruments is worse than those of spectroradiometers. Therefore, the uncertainty of the albedo measurements performed with such instruments is higher than with the spectroradiometer, if the atmospheric conditions remain fairly constant during one spectroradiometric scan. 
Table 2. Agreement between the downwelling erythemal irradiance measured by the SL501 and the spectroradiometer. The mean ratio SL501/Spectroradiometer $\left(r_{m b}\right)$ and the standard deviation $\sigma$ are listed for the SZA ranges occurring during the albedo measurements. Additionally, a separation in cloudless and overcast situations is shown.

\begin{tabular}{lllllll}
\hline SZA range & $47-49.5^{\circ}$ & $49.5-52^{\circ}$ & $52-54.5^{\circ}$ & $54.5-57^{\circ}$ & $57-59.5^{\circ}$ & $59.5-62^{\circ}$ \\
& $r_{m b} \pm \sigma$ & $r_{m b} \pm \sigma$ & $r_{m b} \pm \sigma$ & $r_{m b} \pm \sigma$ & $r_{m b} \pm \sigma$ & $r_{m b} \pm \sigma$ \\
\hline \multirow{2}{*}{ all ratios } & $0.94 \pm 0.17$ & $0.92 \pm 0.21$ & $0.92 \pm 0.18$ & $0.90 \pm 0.17$ & $0.93 \pm 0.03$ & $0.85 \pm 0.19$ \\
cloudless & $0.99 \pm 0.02$ & $0.98 \pm 0.02$ & $0.96 \pm 0.04$ & $0.95 \pm 0.02$ & $0.94 \pm 0.02$ & $0.92 \pm 0.02$ \\
overcast & $0.92 \pm 0.20$ & $0.88 \pm 0.26$ & $0.88 \pm 0.25$ & $0.92 \pm 0.02$ & $0.91 \pm 0.02$ & $0.85 \pm 0.13$ \\
\hline
\end{tabular}

\section{Results}

Table 3 summarises the conditions, when albedo measurements have been performed. In addition, the daily mean albedo values as measured with the SL501 are included in the last column. Results derived from the spectral albedo measurements are not included in Table 3, due to the many different data collection protocols.

\subsection{Spectral albedo}

An overview of daily mean spectral albedo is shown in Table 4. Additionally, the modelled diffuse, as well as direct albedo is included. The spectra are modelled with the tool SNOWALBEDO contained in the libRadtran package, which is based on an albedo model suggested by Wiscombe and Warren (1980). As model input the equivalent depth of liquid water in the snow pack was set to $0.05 \mathrm{gcm}^{-2}$, the mean grain radius to $50 \mu \mathrm{m}$, and the solar zenith angle to $60^{\circ}$. To illustrate the spectral dependence of the albedo, the mean spectral albedo on three different days is shown in Fig. 4. In Fig. 5 the daily mean spectral albedo is shown for a limited wavelength range ( 295 to $500 \mathrm{~nm}$ ), to emphasise the region where the albedo is nearly unity.

The albedo in the UV is between 0.95 and 0.99 . It increases slightly with increasing wavelength, to reach its maximum around 0.99 at $430 \mathrm{~nm}$ on most days (see Fig. 5 and Table 4). The date 5 January 2004 presents an exception with the mean albedo reaching a maximum of 1.01 at $500 \mathrm{~nm}$. The albedo remains high up to $800 \mathrm{~nm}$ in the visible. The decline of the slope for increasing wavelengths is steeper for wavelengths longer than $800 \mathrm{~nm}$ (see Fig. 4). At $1000 \mathrm{~nm}$, the observed albedo ranges between 0.45 and 0.75 . It cannot be decided which albedo spectrum is highest. This depends on wavelength as the spectra cross each other.

In theory such an albedo larger than one is impossible. Dirmhirn and Eaton (1975) state that on cloudless occasions the reflectance of the snow surface has a larger directional component than during overcast situations. The situation on 5 January 2004 was not completely cloud free, but an opaque cirrus layer covered the sky, thus there was a direct component of the incident radiation. In conjunction with a mislevelled sensor this could lead to an albedo of larger than one.

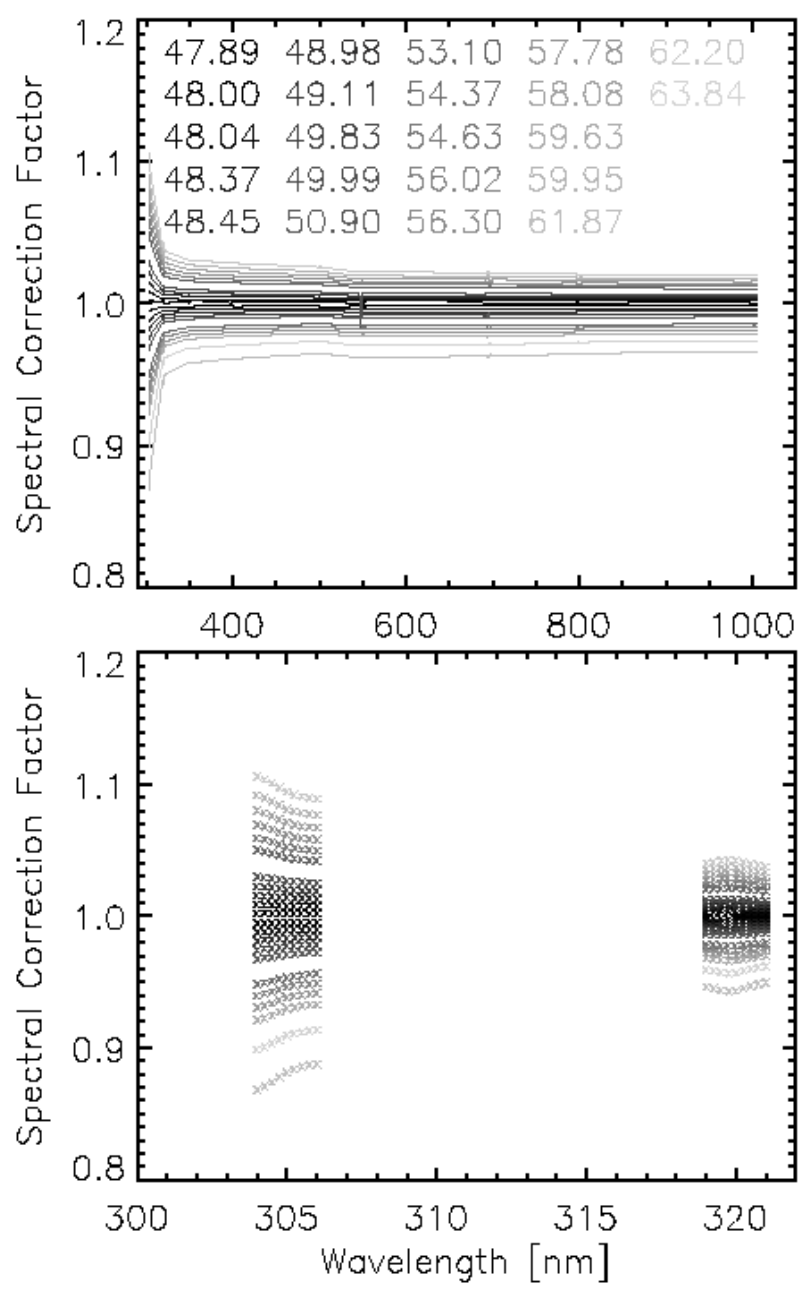

Fig. 3. Modelled correction factor to account for the change in SZA during the albedo measurements for 4 January 2004. The SZA corresponding to the measured downwelling irradiance spectrum is listed in the upper panel, where the complete spectral range is shown. The lower panel only shows the UVB because the spectral dependence of the correction factor is largest in the limited wavelength range. 
Table 3. Summary of the conditions when albedo measurements have been performed. The date, range of SZA, location (NM: Neumayer Station, IE: Ice Edge), type of instrument used (B: Broadband SL501, S: Spectroradiometer), sky conditions, and maximum temperature are shown.

\begin{tabular}{|c|c|c|c|c|c|c|}
\hline Date & SZA range & Location & Type & Sky conditions & $\mathrm{T}_{\max }\left[{ }^{\circ} \mathrm{C}\right]$ & Albedo (SL501) \\
\hline 11.12 .03 & $\begin{array}{l}49.14^{\circ} \text { to } \\
57.48^{\circ}\end{array}$ & $\mathrm{NM}$ & $\mathrm{B}$ & Cloudless sky & -4.8 & 0.96 \\
\hline 19.12 .03 & $\begin{array}{l}50.22^{\circ} \text { to } \\
58.46^{\circ}\end{array}$ & $\mathrm{NM}$ & $\mathrm{B}$ & Overcast & -0.7 & 0.96 \\
\hline 20.12 .03 & $\begin{array}{l}47.52^{\circ} \text { to } \\
50.42^{\circ}\end{array}$ & $\mathrm{NM}$ & $\mathrm{B}$ & $\begin{array}{l}\text { Cirrus, fields of } \\
\text { altocumulus, Sun } \\
\text { sometimes obscured }\end{array}$ & -1.4 & 0.95 \\
\hline 21.12 .03 & $\begin{array}{l}47.23^{\circ} \text { to } \\
62.22^{\circ}\end{array}$ & IE & $\mathrm{B}$ & $\begin{array}{l}\text { Fields of altocumulus, } \\
\text { Sun sometimes behind } \\
\text { thin cirrus clouds }\end{array}$ & -1.3 & 0.91 \\
\hline 22.12 .03 & $\begin{array}{l}47.22^{\circ} \text { to } \\
61.51^{\circ}\end{array}$ & IE & $\mathrm{B}$ & $\begin{array}{l}\text { Sun most of day behind thin } \\
\text { cirrus clouds }\end{array}$ & 0.5 & 0.94 \\
\hline 02.01 .04 & $\begin{array}{l}47.66^{\circ} \text { to } \\
62.00^{\circ}\end{array}$ & $\mathrm{NM}$ & $\mathrm{B}, \mathrm{S}$ & Overcast, stratus & -1.7 & 0.92 \\
\hline 03.01 .04 & $\begin{array}{l}47.75^{\circ} \text { to } \\
57.53^{\circ}\end{array}$ & $\mathrm{NM}$ & $S$ & $\begin{array}{l}\text { Overcast, stratus, } \\
\text { little snow drift }\end{array}$ & 0.4 & N/A \\
\hline 04.01 .04 & $\begin{array}{l}47.85^{\circ} \text { to } \\
60.57^{\circ}\end{array}$ & $\mathrm{NM}$ & $\mathrm{B}, \mathrm{S}$ & $\begin{array}{l}\text { At first overcast (stratus, } \\
\text { stratocumulus), then } \\
\text { cloudless sky }\end{array}$ & -0.1 & 0.93 \\
\hline 05.01 .04 & $\begin{array}{l}47.95^{\circ} \text { to } \\
50.24^{\circ}\end{array}$ & $\mathrm{NM}$ & $\mathrm{B}, \mathrm{S}$ & $\begin{array}{l}\text { Few cirrus and } \\
\text { altocumulus }\end{array}$ & 0.2 & 0.94 \\
\hline 06.01 .04 & $\begin{array}{l}48.49^{\circ} \text { to } \\
49.27^{\circ}\end{array}$ & NM & $\mathrm{B}, \mathrm{S}$ & $\begin{array}{l}\text { Stratocumulus, } \\
\text { sometimes little } \\
\text { transparent }\end{array}$ & 0.3 & 0.96 \\
\hline 08.01 .04 & $\begin{array}{l}48.30^{\circ} \text { to } \\
50.86^{\circ}\end{array}$ & $\mathrm{NM}$ & $\mathrm{B}, \mathrm{S}$ & Overcast stratocumulus & -1.3 & 0.93 \\
\hline
\end{tabular}

\subsection{Broadband albedo}

All albedo values depending on SZA derived from measurements conducted with the SL501 are shown in Fig. 6. The albedo was measured in a range of solar zenith angles from $47^{\circ}$ to $63^{\circ}$. A dependence of albedo on SZA cannot be observed. Except for one occasion, the albedo values are between 0.88 and 0.99. Further, the albedo data have been separated into cloudless and overcast situations. However, a dependence of the albedo on the cloud situation cannot be observed. Overcast and cloud free situations have been distinguished as described in Sect. 3.3.

\subsection{Albedo under cloudless sky}

The afternoon of 4 January 2004 was the longest period where albedo measurements under cloudless sky conditions could be performed. The mean spectral albedo, as well as broadband albedo, shows a tendency of being smaller the later in the day it was measured. Thus, it decreases with increasing SZA. It can clearly be observed in Fig. 7, where the diurnal course of the albedo derived from different radiation sensors is shown. The absolute level of the albedo derived from the measurements with the SL501 is highest. It is lowest for the albedo calculated from pyranometer data collected by the instruments of the Alfred-Wegener-Institute for Polar and Marine Research (AWI).

The deviation in absolute albedo in Fig. 7 is due to the different wavelength sensitivities of the radiation sensors. The AWI pyranometers integrate the incoming radiation from 300 to $3000 \mathrm{~nm}$, the SL501 has a response similar to the erythemal action spectrum (McKinlay and Diffey, 1987). The spectral measurements have been averaged over short wavelength intervals, from 304 to $1004 \mathrm{~nm}$, to display the diurnal cycle. As the SL501 is mainly sensitive to wavelengths in the UVB, it shows the highest albedo on an absolute level. The spectrally averaged albedo comprises not only the UV, but also visible wavelengths, reaching up to $1004 \mathrm{~nm}$, thus being slightly smaller than the SL501 albedo. The albedo derived from pyranometer data is lowest because the largest portion of infrared radiation is included. The location of the AWI instruments is about $200 \mathrm{~m}$ north of the IMUK measuring site. 
Table 4. Daily mean spectral albedo at different wavelengths measured at Neumayer, Antarctica. Values of modelled direct and diffuse albedo are also included. The sampling protocols differed on each day. Therefore, the albedo for some wavelengths is not available (N/A) on some days.

\begin{tabular}{llllllllll}
\hline Date & $305 \mathrm{~nm}$ & $320 \mathrm{~nm}$ & $350 \mathrm{~nm}$ & $400 \mathrm{~nm}$ & $499 \mathrm{~nm}$ & $550 \mathrm{~nm}$ & $695 \mathrm{~nm}$ & $800 \mathrm{~nm}$ & $1000 \mathrm{~nm}$ \\
\hline 02.01 .04 & 0.95 & 0.95 & 0.94 & 0.95 & N/A & N/A & N/A & N/A & N/A \\
03.01 .04 & 0.97 & 0.97 & 0.97 & 0.98 & 0.99 & N/A & 0.95 & 0.90 & 0.76 \\
04.01 .04 & 0.97 & 0.96 & 0.97 & 0.97 & 0.97 & 0.96 & 0.92 & 0.86 & 0.71 \\
05.01 .04 & 0.99 & 0.98 & 0.99 & 1.00 & 1.01 & 1.01 & 0.98 & 0.92 & 0.74 \\
06.01 .04 & 0.98 & 0.97 & 0.98 & 0.98 & 0.97 & 0.97 & 0.90 & 0.83 & 0.65 \\
08.01 .04 & 0.97 & 0.96 & 0.96 & 0.97 & 0.98 & 0.97 & 0.89 & 0.78 & 0.50 \\
mod. diffuse & 0.97 & 0.97 & 0.98 & 0.99 & 0.99 & 0.99 & 0.97 & N/A & N/A \\
mod. direct & 0.98 & 0.98 & 0.98 & 0.99 & 0.99 & 0.99 & 0.97 & N/A & N/A \\
\hline
\end{tabular}

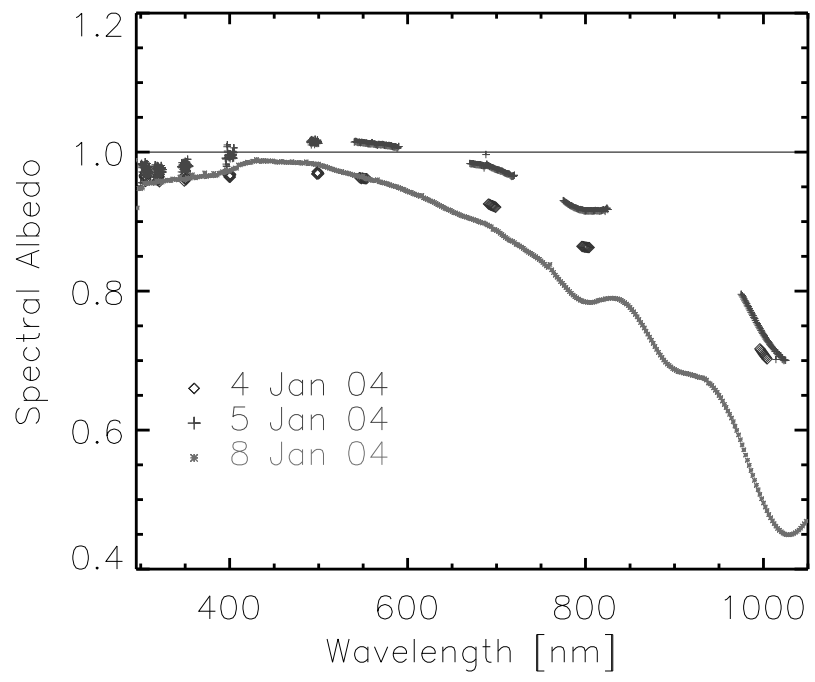

Fig. 4. Daily mean spectral albedo measured at Neumayer on three selected days. The maximum value is reached at about $500 \mathrm{~nm}$. The albedo decreases slightly towards shorter wavelengths. The decrease in albedo for longer wavelengths becomes more pronounced in the infrared for wavelengths greater than $800 \mathrm{~nm}$.

Thus, they detect albedo over a different field of snow, providing independent results.

\subsection{Albedo under overcast sky}

On 2 January 2004, the sky was covered by stratiform clouds. For this day, the diurnal cycle of different integrals of UV albedo is shown in Fig. 8. Additionally to various UV integrals derived from the spectral albedo, the diurnal cycle of albedo measured with the SL501 is shown. No significant diurnal variation depending on SZA can be observed. The daily mean value for each wavelength range derived from the measurements (CIE: McKinlay and Diffey (1987), UVA: 315 to $400 \mathrm{~nm}$, UVB: 290 to $315 \mathrm{~nm}$, UV: 290 to $400 \mathrm{~nm}$ )

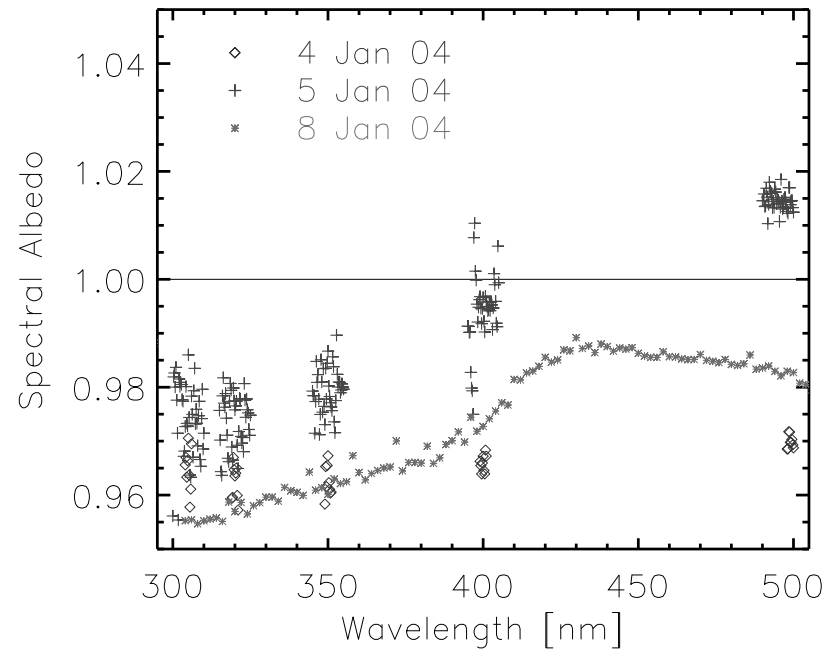

Fig. 5. Same as Fig. 4, but the wavelength range is limited (295 to $505 \mathrm{~nm}$ ). On 5 January 2004, the albedo is larger than unity with 1.015 at $500 \mathrm{~nm}$, which is an effect of direct incidence of solar radiation.

is 0.95 . The daily mean albedo measured with the SL501 is 0.94. This slightly lower value of albedo derived from SL501 data may be due to its nonideal cosine response, which leads to an underestimation of the albedo (see also Sect. 3.3).

\section{Discussion}

The albedo measured at Neumayer agrees to within $\pm 6 \%$ with the albedo of a snow surface experimentally determined in previous studies (Grenfell et al., 1994; Smolskaia et al., 1999). This study focusses on the UV region of the solar spectrum. The data basis at longer wavelengths is even smaller than in the UV and we believe that the measurements in the visible and in the $\mathrm{UV}$, where more than $50 \%$ of the 


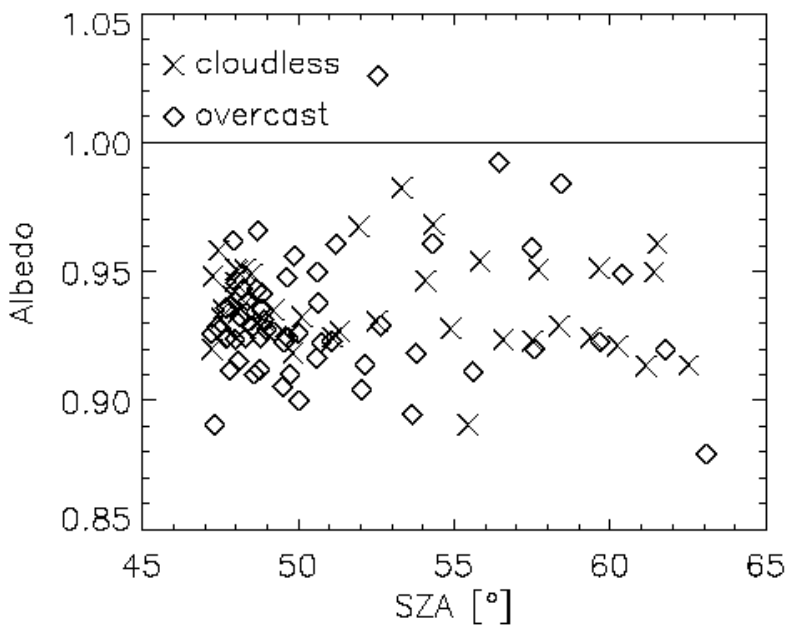

Fig. 6. All albedo values derived from measurements with the SL501 as a function of SZA.

Sun's energy is contained, deserve their own attention. The long wavelengths are believed to have little direct impact on the biota. Further, the spectroradiometer has been intercompared with other spectroradiometers up to $600 \mathrm{~nm}$ only.

Uncertainties due to the way of measuring the albedo with only one sensor have to be discussed. Three main sources of errors lead to uncertainties:

- shadowing effect of the equipment,

- levelling of the sensor after rotating the rod,

- snow surface not being perfectly horizontal due to sastrugi.

\subsection{Shadowing effect}

To determine the shadowing effect of the equipment, the reflectivity of the temperature stabilised box has to be known (see Sect. 3.2). The temperature stabilised box is made of aluminium, which is dull and scratched due to outdoor use and multiple transports. Further, some patches needed for transportation purposes stick on the outside of the box. Therefore, the reflectivity of the box varies across its surface. To determine the mean reflectivity of the box, multiple measurements at different positions are necessary. It was not possible to determine the reflectivity of the temperature stabilised box at IMUK. To determine the reflectivity of a surface according to DIN 5036 (1979), a spectralon plaque of known reflectivity is needed, which had not been available. This was the reason for relying on a reflectivity value of sandblasted aluminium determined by König and Aden (1999).

Further, the spectral dependence of the reflectivity has not been taken into account. Especially in the UVB, some types of aluminium have a much lower reflectivity compared to the visible. This would lead to a spectrally dependent correction of the shadowing effect. The correction factor would be

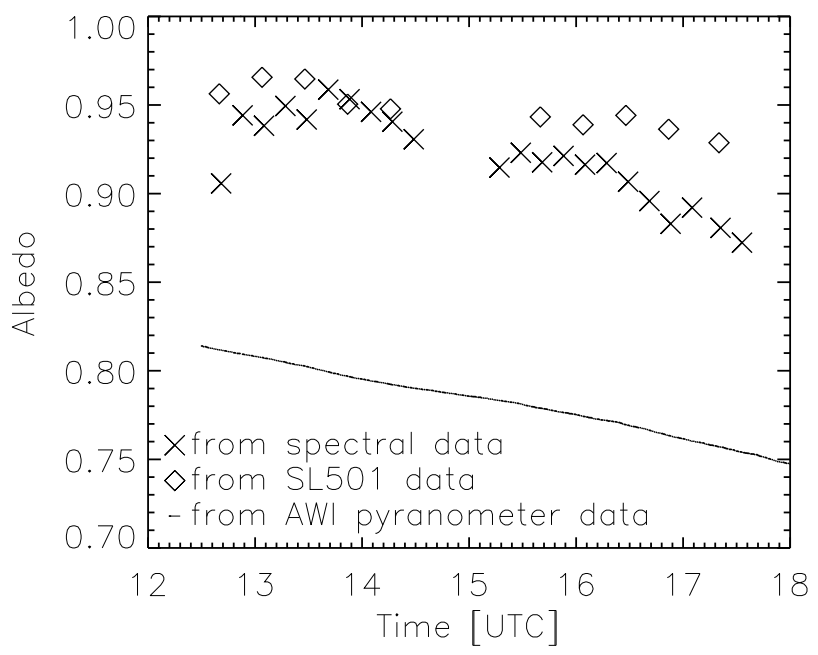

Fig. 7. Diurnal cycle of mean albedo on 4 January 2004 derived from different radiation sensors. For the period shown, the sky was cloud free. All sensors show a decrease in albedo the later in the day it became, thus the larger the solar zenith angle.

larger, the shorter the wavelength. A larger correction factor of the reflected irradiance leads to a larger snow albedo. In this case, the slight spectral decrease in albedo from 1 to 0.96 for decreasing wavelengths from 500 to $300 \mathrm{~nm}$ would be an artifact due to the inaccurate application of a constant correction factor.

Undoubtedly, the shadowing effect of the equipment requires correction, which when applied in this study only represents an approximation of the true shadowing effect. Apart from the spectral dependence or the true reflectivity of the box, possible direct reflections need to be considered in more detail in future studies.

Providing the correction factor increases with decreasing wavelength, the albedo would remain high in the UV range with values between 0.97 and 1 (see Fig. 5).

\subsection{Turning the rod}

Another source of uncertainty arises from turning the rod. Exact levelling of the detector parallel to the horizontal is not possible because it could not properly be controlled. Therefore, the same effect as for an albedo of a sloping surface can be expected. Grenfell et al. (1994) have made observations of albedo for a surface with a slope of $2 \%$ and a solar zenith angle of $70^{\circ}$. The variation in albedo is about $20 \%$, giving apparent albedo values between 0.89 and 1.08 , depending on the direction of the slope and the position of the Sun relative to the slope. For high Sun the slope effect is modest, but at large SZA typical for polar latitudes, it increases rapidly. A perfectly flat surface is almost impossible to encounter on an Antarctic ice shelf, as most areas are covered by sastrugi (snow dunes). Such sastrugi vary in dimension. Their height can range from a few centimetres to $50 \mathrm{~cm}$ and more. In the horizontal one sastrugi can extend over several metres. 


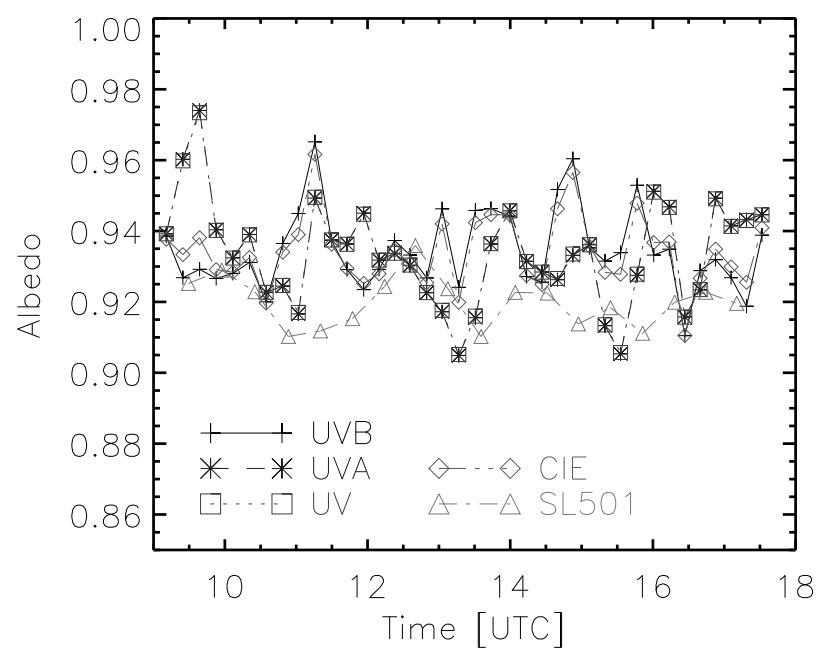

Fig. 8. Diurnal cycle of different integral albedo values measured on 2 January 2004. The sky was covered by stratiform clouds. A dependence of albedo on time (thus SZA) cannot be observed for this day.

Sastrugi tend to reduce the albedo, which is explained in detail by Warren et al. (1998).

The mislevelling is most probably the reason for the outlier albedo value of 1.02 in Fig. 6. Also, the mean spectral albedo being larger than unity on 5 January 2004 can also partly be explained by the mislevelling (see Fig. 4). An albedo larger than one is most likely to be seen during periods with direct incidence. On 5 January 2004, a thin cirrus cloud cover prevailed (see Table 3), facilitating direct incidence of radiation to some extent. However, since the error based on the inaccurate levelling of the detector occurs randomly over the day, the error is reduced the more albedo values are measured. An indication of the uncertainty due to a mislevelled sensor is provided in Fig. 8, where albedo measurements for a whole day are shown. The single albedo values vary within \pm 0.02 , which represents the uncertainty due to levelling the sensor.

\subsection{Overall uncertainty}

A quantification of the overall uncertainty is difficult, as it is hardly possible to quantify each single uncertainty. It could be argued that the spectral behaviour of the snow albedo measured at Neumayer resembles the modelled spectral snow albedo (see Fig. 4), thus providing a valuable result. The modelled snow albedo also decreases with decreasing wavelength. It accounts for the extreme anisotropy of scattering by snow particles using the $\delta$-Eddington approximation for multiple scattering (Lenoble, 1993), together with the Mie theory for single scattering (Liou, 1980). This model has neither been validated with spectral measurements of high resolution for all spectral ranges nor for the UV in general. To be sure of a reliable performance of the snow albedo model, profound validation exercises need to be performed. Until then,

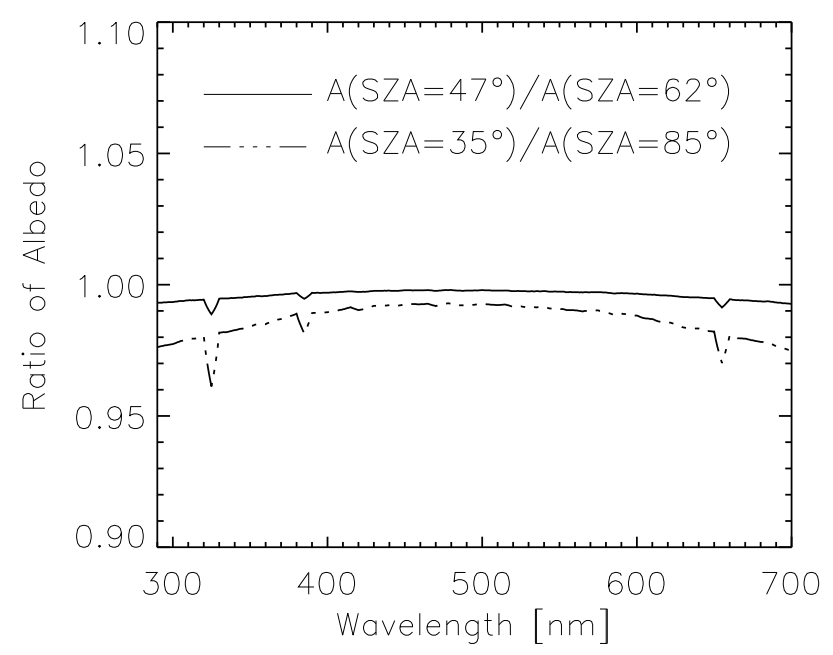

Fig. 9. Ratios of modelled snow albedo (A) for different solar zenith angles. In both cases the ratio is between 0.96 and 1.0 for all wavelengths. Thus, the albedo is larger at larger SZA compared to smaller SZA. The local minima at 320, 385, and $650 \mathrm{~nm}$ are due to Mie scattering processes for single snow grain size radii.

it cannot be proven whether the slight decrease in albedo in the UV is an artifact due to the shadowing effect of the equipment.

\subsection{Effect of SZA}

In previous studies, for example by Grenfell et al. (1994) or Wiscombe and Warren (1980), an increase in albedo for increasing SZA is observed. In contrast, if a dependence of the albedo on SZA can be observed in our measurements, albedo decreases with increasing SZA by 0.08 for an SZA ranging from $48^{\circ}$ at $12: 30$ UTC to $63^{\circ}$ at 17:40 UTC (see Fig. 7). On most days no dependence on SZA has been observed at all (see Fig. 6). For a closer investigation, the albedo for snow is modelled with the tool SNOWALBEDO contained in the libRadtran package, which is based on a model suggested by Wiscombe and Warren (1980). Input parameters are the equivalent depth of liquid water in the snow pack $\left(0.1 \mathrm{~g} / \mathrm{cm}^{2}\right)$, the mean grain radius $(100 \mu \mathrm{m})$, the albedo of the underlying surface (1.0) and a variable SZA. The ratio of spectral albedo modelled with different SZA has been calculated (see Fig. 9). In both albedo ratios the albedo modelled with the larger SZA is in the denominator. Both ratios are below unity by 1 to $3 \%$, depending on the chosen SZA and the wavelength considered. Thus, the albedo is larger for a larger SZA. Under a cloudless sky, the snow albedo increases with increasing SZA because of the strong foreward scattering from the snow grains in the snow cover (Dirmhirn and Eaton, 1975; Li and Zhou, 2003).

The deviation from unity is lowest around $460 \mathrm{~nm}$, increasing towards longer as well as shorter wavelengths. The ratio of albedo spectra modelled with a SZA of $47^{\circ}$ and $63^{\circ}$ represents the total range of SZA under which albedo measurements at Neumayer have been performed. The deviation 


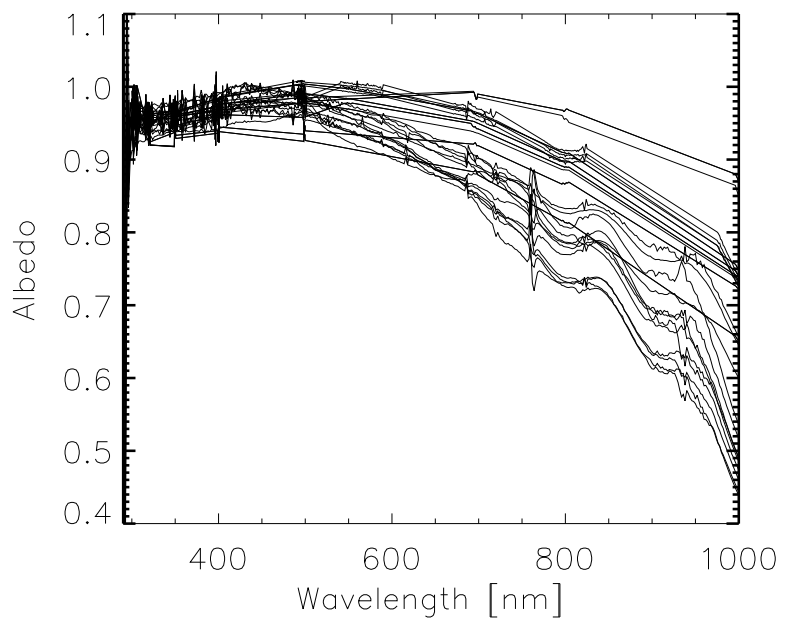

Fig. 10. All of these albedo spectra are measured at Neumayer with solar zenith angles between $48^{\circ}$ and $49^{\circ}$ on different days and times (morning and/or afternoon). The difference in albedo spectra is lowest at $400 \mathrm{~nm}$ with 0.08 and it becomes larger the larger the wavelength.

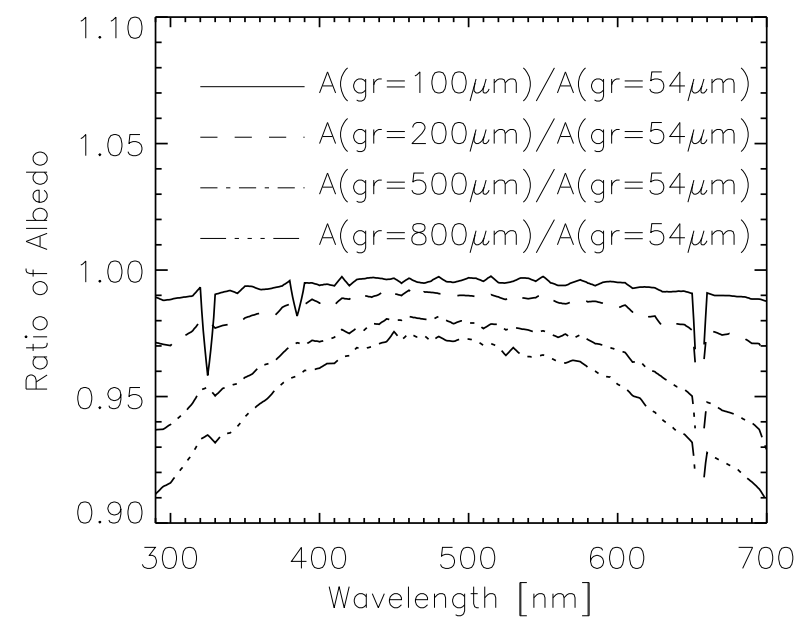

Fig. 11. Ratios of snow albedo (A) modelled with different grain size radii. The larger the grain size, the lower the albedo. The local minima are due to Mie scattering processes.

from unity for this ratio is always below $1 \%$. A more sophisticated model developed by Li and Zhou (2003) also shows a low dependency of albedo on SZA for the UV and visible wavelength range.

The albedo spectra measured at Neumayer with a SZA between $48^{\circ}$ and $49^{\circ}$, but at different times (morning and/or afternoon; different days) even show a deviation of clearly more than $1 \%$ (see Fig. 10). The difference in albedo spectra is lowest at $400 \mathrm{~nm}$ with 0.08 and it becomes larger the larger the wavelength. These observed differences in albedo spectra with the same SZA are based on other parameters, such as snow grain size or cloud conditions. Thus, it is impossible to extract a dependency of the spectral albedo on SZA for our measurements.
During the cloudless afternoon of 4 January 2004 a decline of albedo for increasing SZA is observed with three different instruments (see Fig. 7). This dependency is opposite from the one predicted by theory (Grenfell et al., 1994; Li and Zhou, 2003). A possible levelling error cannot be the source for this observed diurnal cycle, because in particular the AWI instruments are checked regularly and do not need to be rotated. They are mounted to a permanent frame (see http://www.awi-bremerhaven.de/MET/ Neumayer/radiation.html). The reason for this opposite dependence of albedo on SZA is more likely to be based on changing snow conditions due to the steady solar insolation. The same feature has been observed by Pirazzini (2004) for other Antarctic sites. Albedo under a cloudless sky is much more difficult to measure than albedo under a diffuse sky (Grenfell et al., 1994). This is based on the lack of a direct component of incident irradiance for the diffuse (overcast) case. Under diffuse sky conditions, a diurnal dependence of albedo on SZA has not been observed at all (see Fig. 8). This may be due to the wavelength region measured on this day, which was limited to the UV.

\subsection{Effect of snow grain size}

It can be seen in Fig. 11 that the influence of different snow grain sizes on albedo is larger than the effect of SZA. The grain size of the snowflakes increases as the snow ages (Wiscombe and Warren, 1980). The albedo is modelled again with the tool SNOWALBEDO. The parameters are the same as in Fig. 9, but the SZA is constant with $50^{\circ}$. The influence of the grain size is lowest at $460 \mathrm{~nm}$. Between the largest particle $(800 \mu \mathrm{m})$ and the smallest particle $(54 \mu \mathrm{m})$ possible to use as input parameters into SNOWALBEDO, the deviation in modelled albedo is $9 \%$ for $300 \mathrm{~nm}$, as well as for $700 \mathrm{~nm}$. It is roughly $4 \%$ for $460 \mathrm{~nm}$. Realistically, the grain size may have been in the range from $200 \mu \mathrm{m}$ to $54 \mathrm{~nm}$ (Gay et al., 2002). The upper two ratios in Fig. 11 represent these conditions. The deviation in albedo is again largest at $300 \mathrm{~nm}$ and $700 \mathrm{~nm}$, with $3 \%$. Compared to the effect of SZA (see Fig. 9), where the deviation in albedo calculated with the realistic values of SZA are less than $1 \%$, it is shown that the grain size effect is larger compared to the influence of SZA.

The local minima seen at 315,380 and $650 \mathrm{~nm}$ are due to the fact that the model results are based on Mie-calculations, applying single grain sizes and not grain size distributions which occur in nature. Interferences cause these local minima. They appear when the grain size is, for example, a whole-numbered multiple of the wavelength. Thus, these features seen, especially in the solid line ratio, have a physical explanation and are therefore not observable in the measurements.

Snow grain size has not been determined for the Neumayer station during the albedo measurements. However, investigations of snow grain size by Gay et al. (2002) suggest surface grain sizes of 100 to $200 \mu \mathrm{m}$ for a variety of Antarctic locations. As the snow ages the grain sizes become larger. According to Table 3 snow fell on 2 January 2004, so the albedo 
should be larger after this event. Another factor responsible for the aging of snow is the temperature. As snow melts, the grain size increases drastically (Wiscombe and Warren, 1980).

The dependence on grain size may be indicated in our measurements. Snow fell on 2 and 3 January 2004. The albedo is expected to increase after such an event. The daily mean albedo measured with the SL501 shows an increase in albedo from 0.91 on 2 January 2004 to 0.93 on 4 and 5 January 2004. The SL501 albedo on 6 January 2004 may not be representative for the complete day, as it is based on a short time period of roughly one hour. The maximum temperature on 5 and 6 January reached positive values (see Table 3), thus the mean grain radius should have increased comparably fast. On 8 January 2004 a slightly lower albedo was observed as expected for a larger grain size. The low albedo value on 2 January 2004 can also be explained by comparably large particle sizes due to high maximum temperatures during the previous days (i.e. $1.5^{\circ} \mathrm{C}$ on 29 December 2003).

Considering only 5 and 8 January 2004, the mean albedo has been determined from measurements with nearly the same range of SZA (see Table 3). Thus, a change in albedo based on the change in SZA is excluded. On both days a stratiform cloud cover prevailed. The clouds may have been thicker on 8 January 2004, but considering the small data set, these two days represent days with nearly the same cloud conditions. Further, the mean albedo has been determined with 5 and 7 single albedo spectra for 5 and 8 January, respectively. This indicates that possible systematic errors, for example, due to mislevelling the sensors, are ruled out. Thus, most of the factors influencing the albedo, except for the snow grain size, cannot be the source for this observed change. However, the change in albedo of 0.01 from 5 to 8 January 2004 is rather small. Due to the overall measurement uncertainty, it should not be claimed to be able to detect a $1 \%$ change in albedo in a significant way.

Such dependencies are even more difficult to observe in the daily mean albedo spectra (see Figs. 4 and 5). One reason is that they cross each other at different wavelengths. Another reason may be the method of measuring spectral albedo and the uncertainties originating in this method.

For an unambiguous identification of a grain size effect in our measurements, the measurements would have to be separated into bins of equal SZA. However, due to the limited data set, such a separation would not yield statistically significant results. Thus, a larger data set would be desirable. Nevertheless, our findings about the dependence of the albedo on grain size are not in contradiction with earlier studies (Grenfell et al., 1994; Zhou et al., 2001).

\section{Conclusions}

In this study spectral albedo measurements have been carried out at Neumayer Station, Antarctica. Dependencies on parameters influencing the snow albedo, such as SZA or snow grain size, can only partly be seen. One possible explanation of the decrease in albedo (e.g. from 5 to 8 January 2004) is an increase in snow grain size. In contrast, an increase in albedo with increasing SZA could not be detected. For one, this is due to the small range of SZA during albedo measurements. For another, the effect of changing snow conditions outweighs the effect of changing SZA.

A separation of the data set into cloud free and overcast situations did not show albedo values typical for various sky situations. The influence of other factors, therefore, surpasses the effect of cloud cover on albedo. A larger data set is desirable to produce statistically significant results.

To further improve the results of the measured spectral albedo, a thorough consideration of errors and uncertainties in the measurements is vital. In paricular, because the albedo over the Antarctic snow basically reaches unity in the UV and visible part of the solar spectrum, small changes in albedo will lead to relatively large changes in the surface energy budget. A slight spectral dependence of the albedo in the UV has been observed. It could not be conclusively established whether this decrease in albedo in the UV is an artefact due to the shadowing effect of the equipment or whether it is true. However, it can be stated, that the spectral dependence of the albedo in the UV and visible is not very pronounced. Depending on the requirement of accuracy of albedo measurements based on individual applications, spectral measurements of albedo in such a fine resolution are not always necessary. It may be sufficient to use broadband or filter radiometers. This finding is not trivial and was not shown before.

The spectral albedo measurements performed at Neumayer during the summer campaign 2003/2004 serve their purpose of determining the spectral albedo as a basis for the analysis of spectral irradiance and radiance (Wuttke and Seckmeyer, 2006; Wuttke, 2005). The mean spectral albedo measured under a cloudless sky on 4 January 2004 has been used as input into radiative transfer models, simulating the radiative transfer in an Antarctic environment.

Acknowledgements. These studies were financially supported by the Deutsche Forschungsgemeinschaft (DFG) within the "Schwerpunktprogramm Antarktisforschung". Logistic support during the Antarctic campaign was provided by the Alfred-Wegener-Institute Bremerhaven, Foundation for Polar and Marine Research, Germany. Th. Wittemeier of the Institute of Meteorology and Climatology, University of Hannover, has to be thanked for his help with the laboratory measurements necessary for this study.

Topical Editor O. Boucher thanks two referees for their help in evaluating this paper.

\section{References}

Bais, A. F., Gardiner, B. G., Slaper, H., Blumthaler, M., Bernhard, G., McKenzie, R., Webb, A. R., Seckmeyer, G., Kjeldstad, B., Koskela, T., Kirsch, P., Gröbner, J., Kerr, J. B., Kazadzis, S., Leszczynski, K., Wardle, D., Brogniez, C., Josefsson, W., Gillotay, D., Reinen, H., Weihs, P., Svenœ, T., Eriksen, P., Kuik, F., and Redondas, A.: The SUSPEN intercomparison of 
ultraviolet spectroradiometers, J. Geophys. Res., 106, 12 509$12526,2001$.

Bernhard, G. and Seckmeyer, G.: Uncertainty of measurements of spectral solar UV irradiance, J. Geophys. Res., 104, 14 321$14345,1999$.

Blumthaler, M. and Ambach, W.: Solar UVB-Albedo of various Surfaces, Photochem. Photobiol., 48, 85-88, 1988.

Degünther, M., Meerkötter, R., Albold, A., and Seckmeyer, G.: Case study on the influence of inhomogeneous surface albedo on UV irradiance, Geophys. Res. Lett., 98, 3587-3590, 1998.

DIN 5036: Strahlungsphysikalische und lichttechnische Eigenschaften von Materialien, Beuth Verlag GmbH, 1979.

Dirmhirn, I. and Eaton, F.: Some Characteristics of the Albedo of Snow, J. Appl. Meteor., 14, 375-379, 1975.

Feister, U. and Grewe, R.: Spectral Albedo Measurements in the UV and visible region over different types of surfaces, Photochem. Photobiol., 62, 736-744, 1995.

Gay, M., Fily, M., Genthon, C., Frezzotti, M., Oerter, H., and Winther, J.-G.: Snow grain-size measurements in Antartica, J. Glaciol., 48, 527-535, 2002.

Giorgi, F., B., H., Christensen, J., M., H., von Storch, P., Whetton, P., Jones, R., Mearns, L., and Fu, C.: Regional Climate Information - Evaluation and Projections, chap. 10, Climate Change 2001: The Scientific Basis. Contribution of Working Group I to the Third Assessment Report of the Intergovernmental Panel on Climate Change, Cambridge University Press, Cambridge, United Kingdom and New York, NY, USA, 583-638, 2001.

Grenfell, T., Warren, S., and Mullen, P.: Reflection of solar radiation by the Antarctic snow surface at ultraviolet, visible and near-infrared wavelengths, J. Geophys. Res., 99, 18 669-18 694, 1994.

Hansen, J. and Nazarenko, L.: Soot climate forcing via snow and ice albedos, in: Proc. Natl. Acad. Sci., vol. 101, 423-428, 2004.

Houghton, J., Ding, Y., Griggs, D., Noguer, M., van der Linden, P., X., D., Maskell, K., and Johnson, C. (Eds.): Climate Change 2001: The Scientific Basis, contributon of Working Group I to the Third Assessment Report on Climate Change, Cambridge University Press, Cambridge, United Kingdom, 2001.

Jacka, T. H. and Budd, W. F.: Detection of temperature and seaice-extent changes in the Antarctic and Southern Ocean, Ann. Glaciol., 27, 553-559, 1998.

Kondratyev, K. and Cracknell, A.: Observing Global Climate Change, Tayler \& Francis Ltd, London, UK, 1998.

König, H. and Aden, A.: UV reflectance and measurement device, report 2, University of Technology, Helsinki, Finland, 1999.

Kylling, A., Dahlback, A., and Mayer, B.: The Effect of Clouds and Surface Albedo on UV Irradiances at a High Latitude Site, Geophys. Res. Lett., 27, 1411-1414, 2000a.

Kylling, A., Persen, T., Mayer, B., and Svenœ, T.: Determination of an effective spectral surface albedo from ground-based global and direct UV irradiance measurements, J. Geophys. Res., 105, 4949-4959, 2000b.

Lefebre, J., Gallee, H., van Ypersele, J.-P., and Greuell, W.: Modelling of snow and ice melt at ETH camp (West Greenland): a study of surface albedo, J. Geophys. Res., 108, doi:10.1029/2001JD001160, 2003.

Lenoble, J.: Atmospheric Radiative Transfer, A. Deepak Publishing, Hampton, VA, 1993.

Lenoble, J.: Modelling of the influence of snow reflectance on ultraviolet irradiance for cloudless sky, Appl. Opt., 37, 2441-2447, 1998.

Li, S. and Zhou, X.: Assessment of the accuracy of snow surface direct beam spectral albedo under a variety of overcast skies derived by a reciprocal approach through radiative transfer simulation, Appl. Opt., 42, 5427-5441, 2003.

Liou, K. N.: An Introduction to Atmospheric Radiation, vol. 26 of International Geophysics Series, Academic Press, Orlando, 1980.

Mayer, B. and Degünther, M.: Comment on "Measurements of Erythemal Irradiance near Davis Station, Antarctica: Effect of inhomogeneous Surface Albedo", Geophys. Res. Lett., 27, 34893490, 2000.

Mayer, B. and Kylling, A.: Technical note: The libRadtran software package for radiative transfer calculations: Description and examples of use, Atmos. Chem. Phys., 5, 1855-1877, 2005,

SRef-ID: 1680-7324/acp/2005-5-1855.

McKenzie, R., Johnston, P., and Seckmeyer, G.: UV spectroradiometry in the network for the detection of stratospheric change (NDSC), in: Solar Ultraviolet Radiation, Modelling, Measurements and Effects, edited by: Zerefos, C. and Bais, A., Springer, Berlin, 279-287, 1997.

McKenzie, R., Paulin, K., and Madronich, S.: Effects of snow cover on UV irradiance and surface albedo: A case study, J. Geophys. Res., 103, 28 785-28 792, 1998.

McKinlay, A. F. and Diffey, B. L.: A reference action spectrum for ultraviolet induced erythema in human skin, CIE J., 6, 17-22, 1987.

Nichol, S., Pfister, G., Bodeker, G., McKenzie, R., Wood, S., and Bernhard, G.: Moderation of Cloud Reduction of UV in the Antarctic Due to High Surface Albedo, J. Appl. Meteor., 42, 1174-1183, 2003.

Pirazzini, R.: Surface albedo measurements over Antarctic sites in summer, J. Geophys. Res., 109, doi:10.1029/2004JD004617, 2004.

Ricchiazzi, P. and Gautier, C.: Investigation of the effect of surface heterogeneity and topography on the radiation environment of Palmer Station, Antartica, with hybrid 3-D radiative transfer model, J. Geophys. Res., 103, 6161-6176, 1998.

Ricchiazzi, P., Young, S., Gautier, C., and Sowle, D.: A research and teaching software tool for plane-parallel radiative transfer in the Earth's atmosphere, Bull. Am. Meteorol. Soc., 79, 21012114, 1998.

Schmidt, T. and König-Langlo, G.: Radiation Measurements at the German Antarctic Station Neumayer 1982-1992, Reports on Polar Research 146, Alfred Wegener Institute for Polar and Marine Research, Bremerhaven, Germany, 1994.

Schmucki, D., Voigt, S., Philpona, R., Frhlich, C., Lenoble, J., Ohmura, A., and Wehrli, C.: Effective albedo derived from UV measurements in the Swiss Alps, J. Geophys. Res., 106, 53695383, 2001.

Schwander, H., Mayer, B., Ruggaber, A., Albold, A., Seckmeyer, G., and Köpcke, P.: Method to determine snow albedo values in the UV for radiative transfer modelling, Appl. Opt., 38, 38693875, 1999.

Seckmeyer, G., Mayer, B., Bernhard, G., McKenzie, R., Johnston, P., Kotkamp, M., Booth, R., Lucas, T., Mestechkina, T., Roy, C., Gies, H., and Tomlinson, D.: Geographical Differences in the UV measured by Intercompared Spectroradiometers, Geophys. Res. Lett., 22, 1889-1892, 1995.

Seckmeyer, G., Bais, A., Bernhard, G., Blumthaler, M., Eriksen, P., McKenzie, R. L., Roy, C., and Miyauchi, M.: Instruments to measure solar ultraviolet radiation, part I: spectral instruments, WOM-GAW report, 2001.

Seckmeyer, G., Bais, A., Bernhard, G., Blumthaler, M., Booth, R., 
Lantz, K., and McKenzie, R. L.: Instruments to measure solar ultraviolet radiation, part II: Broadband instruments measuring erythemally weighted solar irradiance, WOM-GAW report, 2005.

Slaper, H., Reinen, H. A. J. M., Blumthaler, M., Huber, M., and Kuik, F.: Comparing ground-level spectrally resolved solar UV measurements using various instruments: A technique resolving effects of wavelength shift and slit width, Geophys. Res. Lett., 20, 2721-2724, 1995.

Smolskaia, I., Nunez, M., and Michael, K.: Measurements of Erythemal Irradiance near Davis Station, Antarctica: Effect of Inhomogeneous Surface Albedo, Geophys. Res. Lett., 26, 13811384, 1999.

Smolskaia, I., Masserot, D., Lenoble, J., Brogniez, C., and de la Casiniere, A.: Retrieval of the UV effective snow albedo during 1998 winter campaign in the French Alps, Appl. Opt., 42, 15831587, 2003.

Stamnes, K., Tsay, S. C., Wiscombe, W., and Jayaweera, K.: A numerically stable algorithm for discrete-ordinate-method radiative transfer in multiple scattering and emitting layered media, Appl. Opt., 27, 2502-2509, 1988.

Vaughan, D. G., Marshall, G. J., Connolley, W. M., King, J. C., and Mulvaney, R.: Devil in the Detail, Science, 293, 1777-1779, 2001.

Warren, S., Brandt, R. E., and O'Rawe Hinton, P.: Effect of surface roughness on bi-directional reflectance of Antarctic snow, J. Geophys. Res., 103, 25 789-25 807, 1998.
Weihs, P., Lenoble, J., Blumthaler, M., Martin, T., Seckmeyer, G., Philipona, R., De la Casiniere, A., Sergent, C., Gröbner, J., Cabot, T., Masserot, D., Pichler, T., Pougatch, E., Rengarajan, G., Schmucki, D., and Simic, S.: Modeling the effect of an inhomogeneous surface albedo on incident UV radiation in mountainous terrain: determination of an effective surface albedo, Geophys. Res. Lett., 28, 3111-3114, 2001.

Wiscombe, W. and Warren, S.: A Model for the Spectral Albedo of Snow, I: Pure Snow, J. Atmos. Sci., 37, 2712-2733, 1980.

Wuttke, S.: Radiation Conditions in an Antarctic Environment, Reports on Polar and Marine Research 514, Alfred Wegener Institute for Polar and Marine Research, Bremerhaven, Germany, 2005.

Wuttke, S. and Seckmeyer, G.: Spectral Radiance and Sky Luminance in Antarctica: A Case Study, J. Theor. Appl. Climat., doi:10.1007/s00704-005-0188-2, in press, 2006.

Wuttke, S., Bernhard, G., Ehramjian, J., McKenzie, R., Johnston, P., O'Neill, M., and Seckmeyer, G.: New spectroradiometers complying with the NDSC standards, J. Atmos. Oceanic Technol., in press, 2006.

Zhou, X., Li, S., and Morris, K.: Measurement of all-wave and spectral albedos of snow-covered summer sea ice in the Ross Sea, Antarctica, Ann. Glaciol., 33, 267-274, 2001. 